\title{
Impulse oscillometry for detection of small airway dysfunction in subjects with chronic respiratory symptoms and preserved pulmonary function
}

Liang-Yuan Li ${ }^{1 \dagger}$, Tian-Sheng Yan ${ }^{1 \dagger}$, Jing Yang ${ }^{2}$, Yu-Qi Li ${ }^{1}$, Lin-Xi Fu' ${ }^{1}$ Lan Lan ${ }^{1}$, Bin-Miao Liang ${ }^{1}$, Mao-Yun Wang ${ }^{1 \dagger}$ and Feng-Ming Luo ${ }^{1 *+}$ (D)

\begin{abstract}
Background: Subjects with chronic respiratory symptoms and preserved pulmonary function (PPF) may have small airway dysfunction (SAD). As the most common means to detect $S A D$, spirometry needs good cooperation and its reliability is controversial. Impulse oscillometry (IOS) may complete the deficiency of spirometry and have higher sensitivity. We aimed to explore the diagnostic value of IOS to detect SAD in symptomatic subjects with PPF.

Methods: The evaluation of symptoms, spirometry and IOS results in 209 subjects with chronic respiratory symptoms and PPF were assessed. ROC curves of IOS to detect SAD were analyzed.

Results: 209 subjects with chronic respiratory symptoms and PPF were included. Subjects who reported sputum had higher R5-R20 and Fres than those who didn't. Subjects with dyspnea had higher R5, R5-R20 and AX than those without. CAT and mMRC scores correlated better with IOS parameters than with spirometry. R5, R5-R20, AX and Fres in subjects with $\operatorname{SAD}(n=42)$ significantly increased compared to those without. Cutoff values for IOS parameters to detect SAD were $0.30 \mathrm{kPa} / \mathrm{L} \mathrm{s}$ for R5, $0.015 \mathrm{kPa} / \mathrm{L} \mathrm{s}$ for R5-R20, $0.30 \mathrm{kPa} / \mathrm{L}$ for $A X$ and $11.23 \mathrm{~Hz}$ for Fres. Fres has the largest AUC $(0.665, P=0.001)$ among these parameters. Compared with spirometry, prevalence of SAD was higher when measured with IOS. R5 could detect the most SAD subjects with a prevalence of $60.77 \%$ and a sensitivity of $81 \%$ ( $A \cup C=0.659, P=0.002$ ).

Conclusion: IOS is more sensitive to detect SAD than spirometry in subjects with chronic respiratory symptoms and PPF, and it correlates better with symptoms. IOS could be an additional method for SAD detection in the early stage of diseases.
\end{abstract}

Keywords: Small airway dysfunction, Spirometry, Impulse oscillometry, Preserved pulmonary function

*Correspondence: fengmingluo@outlook.com

'Liang-Yuan Li and Tian-Sheng Yan contributed equally to this work

${ }^{\dagger}$ Mao-Yun Wang and Feng-Ming Luo contributed equally as senior

authors

1 Department of Respiratory and Critical Care Medicine, West China

School of Medicine and West China Hospital, Sichuan University, No. 37 Guoxue Alley, Chengdu 610041, China

Full list of author information is available at the end of the article

\section{Background}

Chronic obstructive pulmonary disease (COPD) and asthma are common chronic respiratory diseases, which may involve small airways. Prospective evidence showed that small airway dysfunction (SAD) might occur prior to the development of COPD and asthma [1-3]. Cough, sputum, dyspnea and wheeze are common symptoms in COPD and asthma patients. SAD may exist in some 
subjects suffered from the above symptoms but with preserved pulmonary function (PPF, the forced expiratory volume in 1 st second $\left(\mathrm{FEV}_{1}\right)$ /forced vital capacity (FVC) ratio $\geq 0.70$ [4]) and negative airway hyper-responsiveness (AHR) or bronchial reversibility (BR), i.e. not meeting the pulmonary function criteria of COPD or asthma. A large multistage stratified sampling survey showed that more than $40 \%$ of Chinese adults aged 20 or older have spirometry-defined SAD [5]. Since the heavy burden of $\mathrm{SAD}$, it is of great importance to take efforts on its early detection and intervention.

Called as "quiet zone", small airways $(<2 \mathrm{~mm}$ internal diameters) account for a small proportion of total airway resistance because of their large cross-sectional area. Currently, the most widely used method in clinic to assess small airway function is spirometry, and the adopted parameters are the forced expiratory flow between 25 and $75 \%$ of $\mathrm{FVC}\left(\mathrm{FEF}_{25-75 \%}\right)$, $\mathrm{FEF}$ at $50 \%$ of $\mathrm{FVC}\left(\mathrm{FEF}_{50 \%}\right)$ and $\mathrm{FEF}$ when $75 \%$ of $\mathrm{FVC}$ has been exhaled $\left(\mathrm{FEF}_{75 \%}\right)$. However, the maneuver requires good cooperation of subjects, and the great variability of values makes their reliability not being unanimously recognized $[6,7]$.

With a different measuring principle from spirometry, impulse oscillometry (IOS) could measure the respiratory mechanical properties during quiet tidal breathing. Compared with spirometry, it is independent of the subjects' efforts because of the externally superimposed oscillation signals [8]. Furthermore, it may have higher sensitivity in detecting SAD and seems to be better correlated with small airway structures [9-11]. Since IOS could reflect the viscous property of the respiratory system by resistance (Rrs), elastic and inertial property by reactance (Xrs), it might provide deeper information on individuals' pathology changes when applied coupled with spirometry.

The present study aimed to explore the diagnostic value of IOS to detect SAD in subjects with chronic respiratory symptoms and PPF. We hypothesized that IOS could be a supplementary method to detect SAD, making up for the deficiency of spirometry, and improving the sensitivity of detection ability. We also intended to compare the correlation between symptoms and IOS as well as spirometry.

\section{Methods}

\section{Study design and subject selection}

This was a single-centered, observational study in which subjects were recruited and tested at the Pulmonary Function Laboratory of West China Hospital, Sichuan University, Chengdu, China between May 1st and September 1st, 2020.

To be included in this study, subjects had to be aged over 18 years and came to receive pulmonary function tests because of chronic respiratory symptoms. Besides, subjects were eligible when they fulfill the criteria of PPF $\left(\mathrm{FEV}_{1} / \mathrm{FVC} \geq 0.70\right)[4]$. Exclusion criteria were as follows: restrictive pulmonary diseases ( $\mathrm{FVC}<80 \%$ predicted), asthma, interstitial lung diseases, structural lung diseases covering active/previous tuberculosis and bronchiectasis, lung cancer, respiratory infection in 2 weeks, myocardial ischemia, history of pulmonary surgery, and incompletion of IOS because of incorrect tongue position, vocal cord closures or swallowing.

We also recruited never-smokers ( $\leq 1$ pack-year of tobacco-smoking history) with normal chest radiogram and without current pulmonary diseases or unstable cardiovascular diseases as healthy controls.

Basic demographic variables including sex, age, weight, height, and body mass index (BMI) were collected. Subjects received IOS, spirometry, and completed a questionnaire covering qualitative and quantitative evaluation of symptoms. Also, bronchial provocation tests or bronchodilator tests were performed to exclude asthma.

The study was approved by the ethics committee of West China Hospital, Sichuan University, and all participants signed an informed consent before the procedure.

\section{Impulse oscillometry}

The respiratory resistance and reactance were measured using IOS equipment (MS-IOS Jaeger) following protocols of ERS [8]. IOS was conducted before spirometry because forced expiration itself might change airway tone [12]. Pressure oscillations generated by a loudspeaker were superimposed onto normal tidal breathing through a mouthpiece for 30 to $45 \mathrm{~s}$, which ranged from 5 to $35 \mathrm{~Hz}$ in frequency. Sitting upright, subjects were asked to wear a nasal clip and exert manual compression on their faces to minimize the influence of cheek vibration and air leak. Three trials were performed and mean values of the following parameters were recorded: respiratory resistance at $5 \mathrm{~Hz}(\mathrm{R} 5)$ and $20 \mathrm{~Hz}(\mathrm{R} 20)$, the difference between R5 and R20 (R5-R20), reactance at $5 \mathrm{~Hz}$ (X5), resonant frequency (Fres) and the area under reactance curve between Fres and $5 \mathrm{~Hz}(\mathrm{AX})$.

\section{Spirometry and bronchodilator/bronchial provocation test} Spirometry was performed by a full MasterScreen PFT System (Jaeger Corp. Germany) according to the American Thoracic Society (ATS)/European Respiratory Society (ERS) guidelines [13]. $\mathrm{FEV}_{1}, \mathrm{FVC}, \mathrm{FEV}_{1}$ / $\mathrm{FVC}, \mathrm{FEF}_{25-75 \%}, \mathrm{FEF}_{50 \%}$ and $\mathrm{FEF}_{75 \%}$ were recorded as percentages of predicted values. The prediction equations are based on a large study of normal spirometry values in Chinese aged 4-80 years, which is recommended in the spirometry guideline in China [14]. SpirometrySAD was defined as at least two of the three small airway indicators $\left(\mathrm{FEF}_{25-75 \%}, \mathrm{FEF}_{50 \%}\right.$ and $\left.\mathrm{FEF}_{75 \%}\right)$ were less 
than $65 \%$ predicted value [5]. To exclude subjects with asthma, most subjects received bronchial provocation tests to confirm negative AHR, and the others received bronchodilator tests in the requirement of negative BR. Bronchial provocation tests were conducted with the Jaeger APS Pro system, following the recommendations of the ATS/ERS guideline [15]. Positive AHR was defined as the provocative dose inducing a $20 \%$ decrease of $\mathrm{FEV}_{1}$ $\left(\mathrm{PD}_{20} \mathrm{FEV}_{1}\right) \leq 2.5 \mathrm{mg}$. For subjects accepted bronchodilator tests, $400 \mu \mathrm{g}$ salbutamol through a metered-dose inhaler was administered and spirometry was repeated after $15 \mathrm{~min}$. BR was positive if the improvement of $\mathrm{FEV}_{1}$ or FVC or both is over $12 \%$ and $200 \mathrm{ml}$ compared with baseline values before inhalation.

\section{Questionnaire}

All participants accepted a questionnaire for qualitative and quantitative evaluation of chronic respiratory symptoms. Chronic respiratory symptoms included cough, sputum, wheeze and dyspnea [16]. Modified Medical Research Council dyspnea scale (mMRC) score and the COPD Assessment Test (CAT) were used to evaluate the severity of symptoms.

\section{Statistical analysis}

Data analysis was performed with SPSS software version

26.0. Continuous variables were expressed as mean $\pm S D$ or median (interquartile range). Categorical variables were expressed as frequency and frequency percentages. Independent $t\left(t^{\prime}\right)$-test, Chi-square test, and Mann-Whitney test were used for statistical difference inferences. Spearman correlation was chosen to determine relationships between spirometry, IOS parameters and symptom scores followed by Holm-Bonferroni correction. With at least two of the three small airway indicators of spirometry $\left(\mathrm{FEF}_{25-75 \%}, \mathrm{FEF}_{50 \%}\right.$ and $\left.\mathrm{FEF}_{75 \%}\right)$ less than $65 \%$ predicted value as the standard of SAD, receiver operator characteristic curves (ROC) were conducted to evaluate the ability of IOS parameters to diagnose SAD. The area under the curve (AUC) and cutoff values were calculated. A P-value less than 0.05 was considered significant.

\section{Results}

Characteristics of study population and healthy controls

Demographics, baseline spirometry and IOS parameters of 85 healthy controls as well as 209 subjects with chronic respiratory symptoms and PPF are shown in Table 1. The quality of all performed spirometry tests were above Grade C according to the ATS/ERS guideline [13]. No significant differences were found in demographic characteristics between symptomatic subjects and healthy controls.

As the best and most common indicators to judge the presence of airflow obstruction, $\mathrm{FEV}_{1}$ and $\mathrm{FEV}_{1} / \mathrm{FVC}$

Table 1 Characteristics of healthy controls and subjects with chronic respiratory symptoms and PPF

\begin{tabular}{|c|c|c|c|}
\hline & $\begin{array}{l}\text { Symptomatic subjects with PPF } \\
(n=209)\end{array}$ & Healthy controls $(n=85)$ & $P$ value \\
\hline \multicolumn{4}{|l|}{ Demographics } \\
\hline Age (years) & $39.53 \pm 12.79$ & $36.92 \pm 10.21$ & 0.067 \\
\hline $\mathrm{BMI}\left(\mathrm{kg} / \mathrm{m}^{2}\right)$ & $22.09 \pm 3.12$ & $22.68 \pm 2.57$ & 0.123 \\
\hline Sex: male, n (\%) & $97(46.4)$ & $40(47.1)$ & 0.920 \\
\hline \multicolumn{4}{|l|}{ Spirometry } \\
\hline $\mathrm{FEV}_{1}(\%$ predicted $)$ & $104.61 \pm 12.41$ & $106.58 \pm 10.73$ & 0.201 \\
\hline FVC (\% predicted) & $105.90 \pm 13.09$ & $106.65 \pm 12.85$ & 0.656 \\
\hline $\mathrm{FEV}_{1} / \mathrm{FVC}$ & $83.78 \pm 6.97$ & $85.16 \pm 5.81$ & 0.108 \\
\hline $\mathrm{FEF}_{25-75 \%}(\%$ predicted $)$ & $86.48 \pm 22.71$ & $93.02 \pm 21.01$ & 0.023 \\
\hline $\mathrm{FEF}_{50 \%}(\%$ predicted $)$ & $90.98 \pm 22.95$ & $100.53 \pm 22.64$ & 0.001 \\
\hline $\mathrm{FEF}_{75 \%}(\%$ predicted $)$ & $81.37 \pm 30.57$ & $85.50 \pm 27.61$ & 0.281 \\
\hline \multicolumn{4}{|l|}{ IOS } \\
\hline $\mathrm{R} 5$ (kPa/L s) & $0.32 \pm 0.07$ & $0.28 \pm 0.06$ & $<0.001$ \\
\hline R20 (kPa/L s) & $0.29 \pm 0.06$ & $0.26 \pm 0.06$ & $<0.001$ \\
\hline R5-R20 (kPa/L s) & $0.0219 \pm 0.0273$ & $0.0193 \pm 0.0238$ & 0.449 \\
\hline X5 (kPa/L s) & $-0.1009 \pm 0.0279$ & $-0.1007 \pm 0.0280$ & 0.966 \\
\hline Fres $(\mathrm{Hz})$ & $11.38 \pm 2.58$ & $10.49 \pm 2.10$ & 0.005 \\
\hline $\mathrm{AX}(\mathrm{kPa} / \mathrm{L})$ & $0.24(0.17,0.34)$ & $0.20(0.14,0.30)$ & 0.015 \\
\hline
\end{tabular}

The data are presented as mean $\pm S D$ for normally distributed variables and median (interquartile range) for nonnormally distributed variables $B M I$ body mass index 
were not significantly different in the two groups. Despite $\mathrm{FEF}_{25-75 \%}$ and $\mathrm{FEF}_{50 \%}$ of symptomatic subjects statistically lower than controls, they were still within the normal range.

For IOS parameters, R5, R20, Fres and AX were significantly higher in symptomatic subjects with PPF than healthy controls. But R5-R20 and X5 did not differ between groups.

\section{Relationship between symptoms, spirometry and IOS parameters}

In 209 subjects with chronic respiratory symptoms and PPF, no spirometry or IOS parameters were different between subjects with and without cough/ wheeze. Subjects who reported symptom of sputum had higher R5-R20 $(0.0274 \pm 0.0271 \mathrm{kPa} / \mathrm{L} \mathrm{s}$ versus $0.0179 \pm 0.0269 \mathrm{kPa} / \mathrm{L} \mathrm{s}, \mathrm{P}=0.012$, Fig. $1 \mathrm{~b})$ and Fres $(11.90 \pm 2.62 \mathrm{~Hz}$ versus $11.00 \pm 2.50 \mathrm{~Hz}, \mathrm{P}=0.012$, Fig. 1d) compared those without sputum. Those who reported dyspnea had higher $\mathrm{R} 5(0.34 \pm 0.07 \mathrm{kPa} / \mathrm{L} \mathrm{s}$ versus $0.31 \pm 0.06 \mathrm{kPa} / \mathrm{L} \mathrm{s}, \mathrm{P}=0.027$, Fig. 1a), R5-R20 $(0.0296 \pm 0.0284 \mathrm{kPa} / \mathrm{L}$ s versus $0.0198 \pm 0.0268 \mathrm{kPa} / \mathrm{L} \mathrm{s}$, $\mathrm{P}=0.033$, Fig. $1 \mathrm{~b})$ and $\mathrm{AX}(0.32 \pm 0.18 \mathrm{kPa} / \mathrm{L}$ versus $0.26 \pm 0.15 \mathrm{kPa} / \mathrm{L}, \mathrm{P}=0.027$, Fig. 1c) compared with those did not. Among spirometry parameters, only $\mathrm{FEF}_{75 \%}$ was significantly different between subjects with and without dyspnea $(73.44 \pm 28.78 \%$ predicted versus $83.54 \pm 30.77 \%$ predicted, $\mathrm{P}=0.049$ ).

When it came to the quantitative evaluation of symptoms (Table 2), no spirometry parameters were associated with the mMRC score. However, R5, R5-R20, and AX were significantly correlated with the dyspnea score, although they did not survive conservative Bonferroni correction. As for the CAT score, significant correlations were observed in $\mathrm{FEV}_{1} / \mathrm{FVC}$ and $\mathrm{FEF}_{75 \%}$ for spirometry, but they failed to survive Bonferroni correction. All IOS parameters were significantly correlated with CAT score, especially R5, despite failures of R20 and R5-R20 to survive Bonferroni correction.

$\mathrm{FEV}_{1} / \mathrm{FVC}, \mathrm{FEF}_{25-75 \%}, \mathrm{FEF}_{50 \%}$ and $\mathrm{FEF}_{75 \%}$ were significantly correlated with all IOS parameters except for X5 after correlation analysis with Bonferroni correction (Table 3). The strongest correlation was observed between $\mathrm{FEF}_{25-75 \%}, \mathrm{FEF}_{50 \%}, \mathrm{FEF}_{75 \%}$ and $\mathrm{R} 5(\mathrm{r}=0.37$, $\mathrm{P}<0.001$ for all). Moderate correlations were also found between R5-R20, AX, Fres and the three small airway parameters of spirometry.

\section{Characteristics of the subjects with and without SAD}

Classified according to the presence of spirometry defined SAD, demographics and clinical features of the subjects with chronic respiratory symptoms and PPF
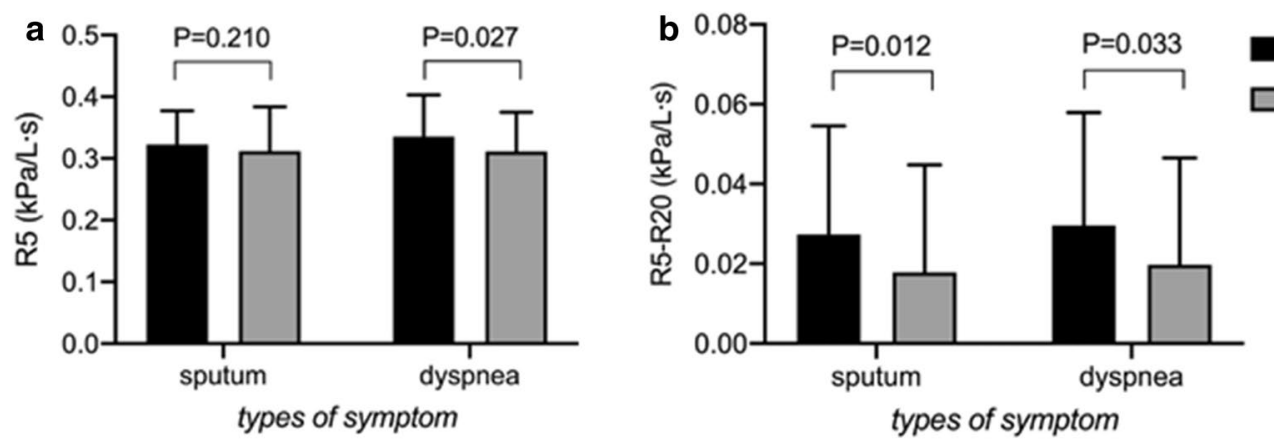

symptom (+)

symptom (-)

C
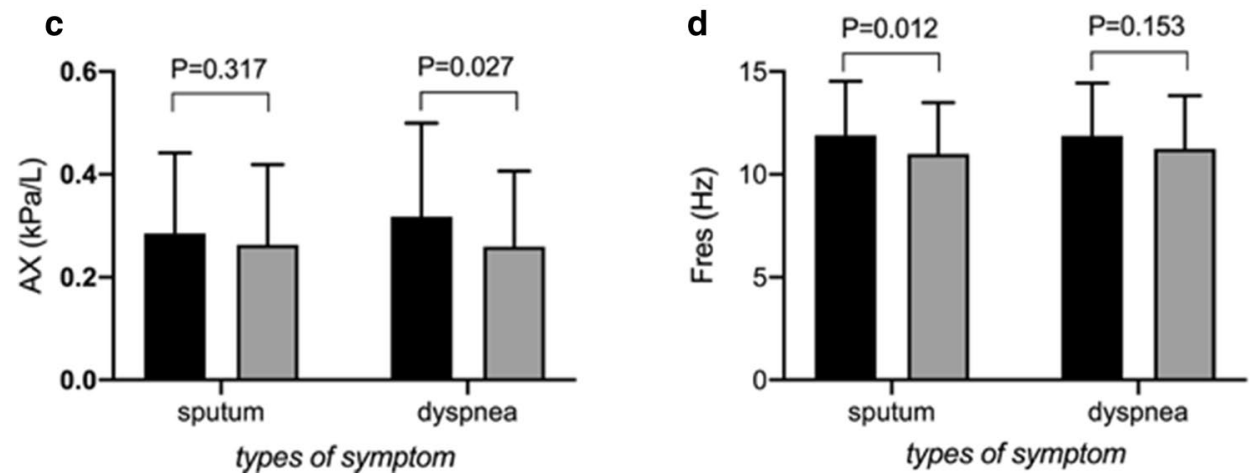

types of symptom

Fig. 1 a R5, b R5-R20, c AX, d Fres were plotted for subjects with PPF from the symptom (+) versus symptom (-) groups according to the two specified symptoms (sputum and dyspnea). Bar charts represented mean +SD 
Table 2 Spearman correlation coefficients of symptom scores with spirometry and IOS parameters in subjects with chronic respiratory symptoms and PPF $(n=209)$

\begin{tabular}{|c|c|c|c|c|c|c|}
\hline Spirometry parameter & $\mathrm{FEV}_{1} \%$ & FVC \% & $\mathrm{FEV}_{1} / \mathrm{FVC}$ & $\mathrm{FEF}_{25-75 \%} \%$ & $\mathrm{FEF}_{50 \%} \%$ & $\mathrm{FEF}_{75 \%} \%$ \\
\hline $\mathrm{mMRC}$ & -0.004 & 0.021 & -0.072 & -0.082 & -0.084 & -0.126 \\
\hline CAT & 0.029 & 0.112 & $-0.188^{* *}$ & -0.135 & -0.124 & $-0.169^{*}$ \\
\hline IOS parameter & R5 & R20 & R5-R20 & $\mathrm{X} 5$ & $A X$ & Fres \\
\hline mMRC & $0.150^{*}$ & 0.111 & $0.162^{*}$ & -0.127 & $0.179^{* *}$ & 0.131 \\
\hline CAT & $0.243^{* *}$ & $0.174^{*}$ & $0.150^{*}$ & $-0.200^{* *}$ & $0.204^{* *}$ & $0.212^{* *}$ \\
\hline
\end{tabular}

$\mathrm{FEV}_{1}, \mathrm{FVC}, \mathrm{FEF}_{25-75 \%}, \mathrm{FEF}_{50 \%}$ and $\mathrm{FEF}_{75 \%}$ are expressed as \% predicted

Values in italic indicate significant correlations after Bonferroni correction

*P $<0.05$

**P $<0.01$

Table 3 Correlation between spirometry and IOS parameters in subjects with chronic respiratory symptoms and PPF $(n=209)$

\begin{tabular}{|c|c|c|c|c|c|c|c|c|c|c|c|c|}
\hline \multirow[t]{2}{*}{ IOS parameter } & \multicolumn{2}{|c|}{$\mathrm{FEV}_{1}$ (\% predicted) } & \multicolumn{2}{|c|}{ FVC (\% predicted) } & \multicolumn{2}{|c|}{$\mathrm{FEV}_{1} / \mathrm{FVC}$} & \multicolumn{2}{|c|}{$\begin{array}{l}\mathrm{FEF}_{25-75 \%}(\% \\
\text { predicted) }\end{array}$} & \multicolumn{2}{|c|}{$\begin{array}{l}\mathrm{FEF}_{50 \%}(\% \\
\text { predicted) }\end{array}$} & \multicolumn{2}{|c|}{$\begin{array}{l}\mathrm{FEF}_{75 \%}(\% \\
\text { predicted) }\end{array}$} \\
\hline & $r$ & P value & $r$ & $P$ value & $r$ & $P$ value & $r$ & $P$ value & $r$ & P value & $r$ & $P$ value \\
\hline R5 & -0.15 & 0.033 & 0.04 & 0.526 & -0.23 & 0.001 & -0.37 & $<0.001$ & -0.37 & $<0.001$ & -0.37 & $<0.001$ \\
\hline R20 & -0.12 & 0.092 & 0.01 & 0.923 & -0.08 & 0.243 & -0.26 & $<0.001$ & -0.28 & $<0.001$ & -0.23 & 0.001 \\
\hline R5-R20 & -0.07 & 0.293 & 0.09 & 0.208 & -0.33 & $<0.001$ & -0.27 & $<0.001$ & -0.23 & 0.001 & -0.35 & $<0.001$ \\
\hline$\times 5$ & 0.13 & 0.068 & 0.09 & 0.211 & -0.02 & 0.791 & 0.19 & 0.005 & 0.19 & 0.005 & 0.16 & 0.018 \\
\hline$A X$ & -0.17 & 0.013 & -0.05 & 0.471 & -0.16 & 0.020 & -0.30 & $<0.001$ & -0.28 & $<0.001$ & -0.29 & $<0.001$ \\
\hline Fres & -0.13 & 0.069 & 0.03 & 0.623 & -0.28 & $<0.001$ & -0.30 & $<0.001$ & -0.28 & $<0.001$ & -0.31 & $<0.001$ \\
\hline
\end{tabular}

Values in italic indicate significant correlations after Bonferroni correction

were shown in Table 4. No differences were found in both qualitative and quantitative assessment of chronic respiratory symptoms. In spirometry parameters, not only the three small airway parameters $(\mathrm{P}<0.001$ for all $)$ but also $\mathrm{FEV}_{1}$ and $\mathrm{FEV}_{1} / \mathrm{FVC}$ decreased in subjects with SAD.

IOS parameters related to small airways increased in subjects with spirometry defined SAD compared with those that didn't have SAD (Fig. 2). R5 was a little higher in SAD group $(0.34 \pm 0.07 \mathrm{kPa} / \mathrm{L} \mathrm{s})$ than group without SAD $(0.31 \pm 0.06 \mathrm{kPa} / \mathrm{L} \mathrm{s}, \mathrm{P}=0.005$, Fig. $2 \mathrm{a}) . \mathrm{R} 5-\mathrm{R} 20$ of SAD group was nearly two times higher than that of no SAD $(0.0352 \pm 0.0321 \mathrm{kPa} / \mathrm{L}$ s versus $0.0185 \pm 0.0250 \mathrm{kPa} / \mathrm{L} \mathrm{s}$, $\mathrm{P}=0.003$, Fig. 2c) while there was no difference in $\mathrm{R} 20$ $(0.31 \pm 0.06 \mathrm{kPa} / \mathrm{L}$ s versus $0.29 \pm 0.06 \mathrm{kPa} / \mathrm{L} \mathrm{s}, \mathrm{P}=0.152$, Fig. 2b). Meantime, no difference in X5 was observed between two groups $(-0.1062 \pm 0.0318 \mathrm{kPa} / \mathrm{L} \mathrm{s}$ versus $0.0995 \pm 0.0267 \mathrm{kPa} / \mathrm{L} \mathrm{s}, \mathrm{P}=0.166$, Fig. $2 \mathrm{~d}$ ), but $\mathrm{AX}$ was significantly higher in $\mathrm{SAD}$ subjects compared with those without it $[0.31(0.20,0.48) \mathrm{kPa} / \mathrm{L}$ versus $0.23(0.16,0.31)$ $\mathrm{kPa} / \mathrm{L}, \mathrm{P}=0.002$, Fig. 2e]. Significantly increased Fres was also observed in SAD group $(12.87 \pm 3.30 \mathrm{~Hz})$ compared with the one without SAD $(11.01 \pm 2.23 \mathrm{~Hz}, \mathrm{P}=0.001$, Fig. 2f).

\section{The value of IOS parameters to detect SAD in the study} population

With SAD standard taken as at least two of the three small airway indicators of spirometry $\left(\mathrm{FEF}_{25-75 \%}\right.$, $\mathrm{FEF}_{50 \%}$ and $\mathrm{FEF}_{75 \%}$ ) less than $65 \%$ predicted, we conducted ROC analyses of IOS parameters which were significantly different between groups with and without SAD. And the cutoff values were determined as follows: R5 greater than $0.30 \mathrm{kPa} / \mathrm{L} \mathrm{s}, \mathrm{R} 5-\mathrm{R} 20$ greater than $0.015 \mathrm{kPa} / \mathrm{L} \mathrm{s}, \mathrm{AX}$ greater than $0.30 \mathrm{kPa} / \mathrm{L}$, and Fres greater than $11.23 \mathrm{~Hz}$ (Table 5). Among these parameters, Fres had the largest AUC [0.665 (95\% CI $0.564-0.766$ )] yield a sensitivity of $69 \%$ and specificity of $58.7 \%$. In addition, R5 had the highest sensitivity of 81\% [AUC, 0.659 (95\% CI 0.563-0.754)] while AX had the highest specificity of $71.9 \%$ [AUC, 0.656 (95\% CI 0.557-0.756)] (Table 5 and Fig. 3).

Compared with spirometry, R5, R5-R20, AX and Fres could detect more SAD in subjects with chronic respiratory symptoms and PPF (Fig. 4). Among these IOS parameters, R5 determined the highest prevalence of SAD. 
Table 4 Features and spirometry parameters of subjects with and without spirometry-SAD

\begin{tabular}{|c|c|c|c|}
\hline & $\begin{array}{l}\text { SAD } \\
n=42(20.1 \%)\end{array}$ & $\begin{array}{l}\text { no SAD } \\
n=167(79.9 \%)\end{array}$ & P value \\
\hline \multicolumn{4}{|c|}{ Demographics and clinical history } \\
\hline Age (years) & $41.81 \pm 12.56$ & $38.95 \pm 12.82$ & 0.196 \\
\hline BMI $\left(\mathrm{kg} / \mathrm{m}^{2}\right)$ & $22.97 \pm 3.16$ & $21.86 \pm 3.08$ & 0.039 \\
\hline Sex: male, n (\%) & $21(50.0)$ & $76(45.5)$ & 0.602 \\
\hline \multicolumn{4}{|c|}{ Chronic respiratory symptoms } \\
\hline Cough, n (\%) & $32(76.2)$ & $145(86.8)$ & 0.087 \\
\hline Sputum, n (\%) & $18(42.9)$ & $70(41.9)$ & 0.912 \\
\hline Wheeze, n (\%) & $17(40.5)$ & $55(32.9)$ & 0.358 \\
\hline Dyspnea, n (\%) & $13(31.0)$ & $32(19.2)$ & 0.097 \\
\hline $\mathrm{mMRC}$ & $0(0,1)$ & $0(0,0)$ & 0.493 \\
\hline CAT & $7(4,9)$ & $6(3,8)$ & 0.204 \\
\hline \multicolumn{4}{|l|}{ Spirometry parameters } \\
\hline $\mathrm{FEV}_{1}(\%$ predicted $)$ & $95.65 \pm 9.57$ & $106.86 \pm 12.04$ & $<0.001$ \\
\hline FVC (\% predicted) & $107.09 \pm 11.25$ & $105.60 \pm 13.53$ & 0.513 \\
\hline $\mathrm{FEV}_{1} / \mathrm{FVC}$ & $75.29 \pm 3.10$ & $85.92 \pm 5.97$ & $<0.001$ \\
\hline $\mathrm{FEF}_{25-75 \%}(\%$ predicted $)$ & $57.35 \pm 6.26$ & $93.80 \pm 19.18$ & $<0.001$ \\
\hline $\mathrm{FEF}_{50 \%}(\%$ predicted $)$ & $60.77 \pm 6.11$ & $98.58 \pm 19.02$ & $<0.001$ \\
\hline $\mathrm{FEF}_{75 \%}(\%$ predicted $)$ & $51.62 \pm 10.24$ & $88.85 \pm 19.40$ & $<0.001$ \\
\hline
\end{tabular}

The data are presented as mean \pm SD

\section{Discussion}

In the present study, we find that IOS might be a useful measurement for detection of SAD in subjects with chronic respiratory symptoms and PPF. Its higher sensitivity and easier implementation make up for the deficiency of spirometry. Besides, IOS parameters seem to correlate better with symptoms than spirometry.

Our target study population is symptomatic subjects with PPF. The subjects suffer from COPD/asthma-like symptoms but having normal $\mathrm{FEV}_{1} / \mathrm{FVC}$ which is not different from healthy controls. IOS parameters including R5, R20, Fres and AX significantly increase in symptomatic subjects. The same trend was also observed in several other studies which focus on the comparison of patients with self-reported symptoms but normal spirometry and healthy people [17], or studies comparing the symptomatic and asymptomatic PPF cohorts after environmental exposure $[10,18]$. All these findings shed light on the possible location of injury which results in symptoms in subjects with PPF is more distal and could be better detected by IOS than conventional spirometry.

More and more studies $[9,11,19]$ found that spirometry was not sensitive to assess small airway function. Xiao et al. [5] found that $\mathrm{FEF}_{25-75 \%}$ was often within the normal range when $\mathrm{FEV}_{1} / \mathrm{FVC}$ was above $75 \%$. Besides, the forced expiration depends greatly on subject's effort and the maneuver itself might alter bronchomotor tone [20]. In contrast, IOS could distinguish signals
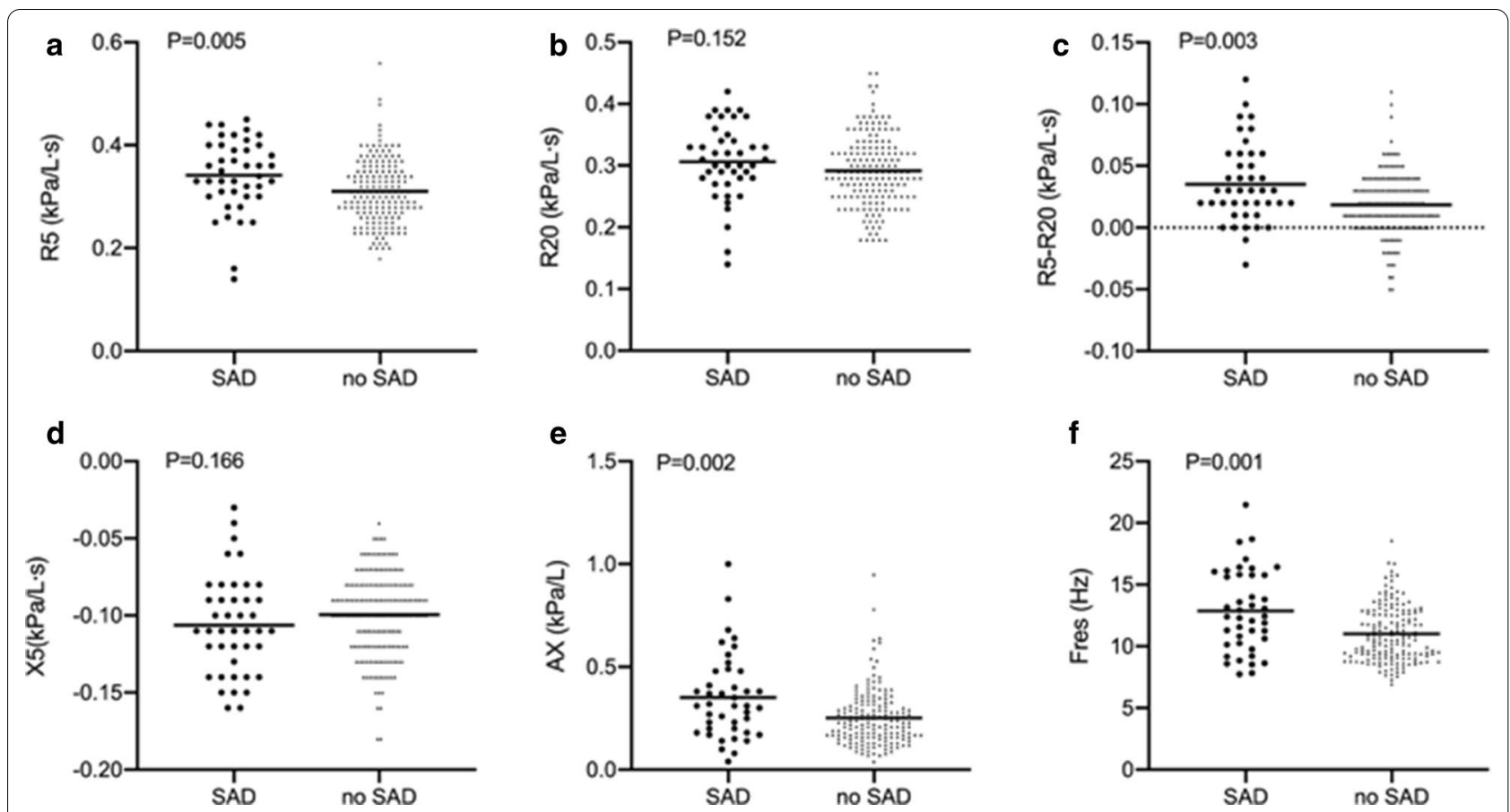

Fig. 2 IOS parameters including a R5, b R20, c R5-R20, d X5, e AX and f Fres were plotted for subjects with chronic respiratory symptoms and PPF from the SAD versus no SAD groups. The bars represented means 
Table 5 Cutoff values of IOS parameters for the prediction of SAD in subjects with chronic respiratory symptoms and PPF $(\mathrm{n}=\mathbf{2 0 9 )}$

\begin{tabular}{lllllllll}
\hline IOS parameter & Cutoff value & AUC & Sensitivity (\%) & Specificity (\%) & LR (+) & LR (-) & Youden index & P value \\
\hline R5 & 0.30 & 0.659 & 81.0 & 44.3 & 1.45 & 0.43 & 0.25 & 0.002 \\
R5-R20 & 0.015 & 0.646 & 76.2 & 47.3 & 1.45 & 0.50 & 0.24 & 0.004 \\
AX & 0.30 & 0.656 & 57.1 & 71.9 & 2.03 & 0.60 & 0.28 & 0.002 \\
Fres & 11.23 & 0.665 & 69.0 & 58.7 & 1.67 & 0.53 & 0.28 & 0.001 \\
\hline
\end{tabular}

$A \cup C$ area under curve, $L R$ likelihood ratio

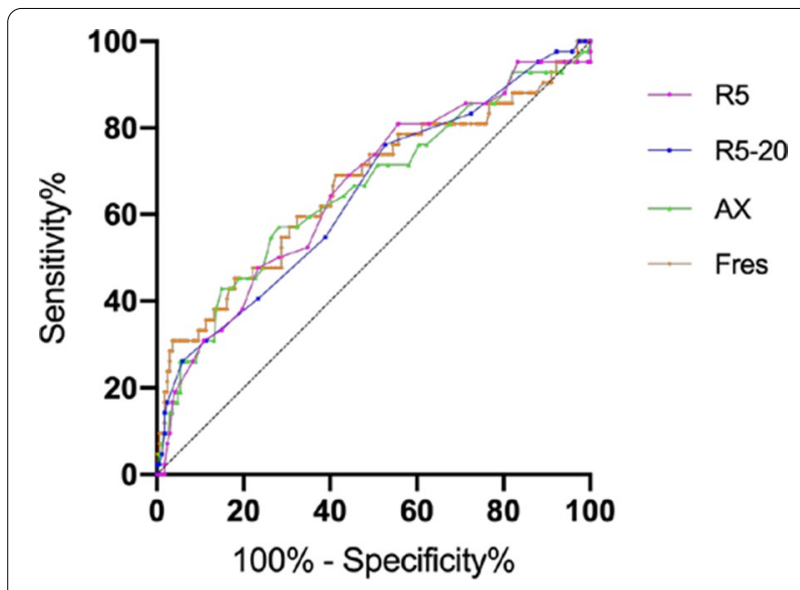

Fig. 3 ROC curves of IOS parameters (R5, R5-R2O, AX, Fres) in detecting SAD identified by small airway parameters of spirometry

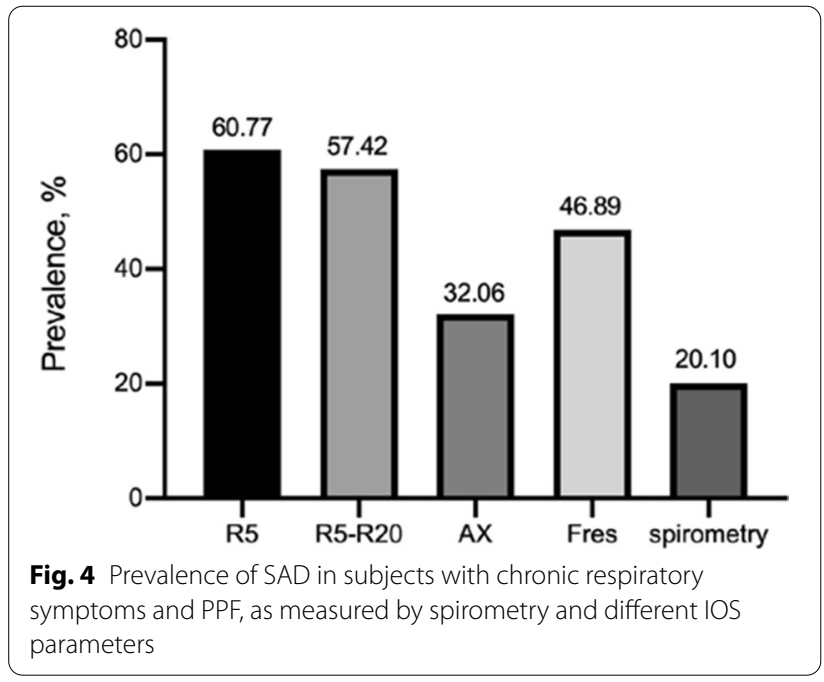

from different lung regions to provide comprehensive information on regional heterogeneity [11]. These might explain the reason why the correlations between spirometry and IOS parameters are not strong in the present study. Even so, IOS parameters related to small airways, namely R5, R5-R20, AX and Fres correlate relatively better with the three small airway indicators of spirometry.

When subjects were classified into with and without SAD according to the spirometry-SAD standard, exactly the above four IOS parameters associated with small airway function significantly differed between groups. Representing the total (central and distal) airway resistance, R5 may rise due to the increase of distal airway resistance [21]. R5-R20 reflects the resistance of peripheral airways and the regional ventilation heterogeneity [11]. Its value represents the degree of frequency dependency, which is usually absent in healthy adults [8]. AX is related to peripheral lung compliance and small airway patency [22]. As the frequency at which reactance is zero, meaning equal and opposite inertial and elastic properties at this frequency [23], Fres reflects the capacitance and inertial properties of peripheral airways [11]. Except for the above four parameters, decreases in X5 were also observed in other studies $[17,19,24]$ which compared subjects with and without symptoms or SAD. However, $\mathrm{X} 5$ is not different between SAD and no SAD group in the present study. Reflecting the dynamic compliance of respiratory system, it is affected not only by the elasticity of respiratory system itself but also by the airflow resistance i.e. time constants $[8,25]$. The failure to find a difference in X5 may be due to the unimpaired elasticity and lung volume. Besides, the relatively mild symptoms and lesions in our study population might represent that the degree of expiratory flow limitation (EFL) is relatively mild. However, EFL manifests in the difference of reactance between inspiratory and expiratory phase, while X5 reflects the mean reactance during the whole breath.

Compared with spirometry, the prevalence of SAD is higher when it is recalculated with IOS cutoff values, which has also been confirmed in previous studies [10, $11,19,24]$. IOS could detect airway dysfunction that spirometry failed to $[9,26]$. Consistent with the prior study [24], Fres seems to perform the best in diagnosing SAD on account of the largest AUC. However, R5 and R5-R20 have the highest sensitivity and might be more suitable as screening indexes. When it comes to the exact diagnosis in clinic, either high sensitivity or specificity of the individual index might demand a comprehensive 
consideration of various IOS and spirometry indexes. In addition, the cutoff values obtained in our study are generally lower than those in previous studies. For R5-R20, abnormal cutoff values were concluded as $0.03 \mathrm{kPa} / \mathrm{L} \mathrm{s}$ [26] or $0.07 \mathrm{kPa} / \mathrm{L} \mathrm{s}[24,27]$, greatly different from the $0.015 \mathrm{kPa} / \mathrm{L} \mathrm{s}$ in the present study. A study [28] used the upper limit $(0.35 \mathrm{kPa} / \mathrm{L} \mathrm{s})$ of above 400 normal subjects as the critical value for R5, which was also a little higher than our value of $0.30 \mathrm{kPa} / \mathrm{L} \mathrm{s}$. The interindividual variation of IOS values, which is not good as spirometry in this regard [12], together with the different SAD standards, disease severity, and race of the study population might result in the differences of cutoff values.

Apart from the high sensitivity, IOS also performs better in the association with specified symptoms than spirometry. R5-R20 and Fres are significantly increased in subjects with sputum than those without. Similarly, subjects with dyspnea have higher R5, R5-R20 and AX. The above parameters are all related to peripheral airways. Sputum production reflects the increase of inflammatory mediators in the lung. Previous results were consistent with our findings, suggesting that the place of airway inflammation, obstruction and injury in such symptomatic patients with PPF is predominated with small airways [17, 24]. Except for the increased $\mathrm{FEF}_{75 \%}$ in subjects with dyspnea, most spirometry parameters failed to identify the difference between subjects with and without specified symptoms. We also evaluated the symptoms quantitatively using mMRC and CAT scores to explore the correlation of IOS and spirometry results with the severity of symptoms. Although the relationships between severity of dyspnea and IOS parameters are weak and fail to survive Bonferroni correction, no relationship is observed for spirometry results. Besides, Bonferroni correction is so strict that could result in the possibility of false negativity. The correlations between comprehensive evaluation for all symptoms (CAT score) and IOS parameters are also stronger than spirometry indicators. In spite of previous use of CAT score in eversmokers with PPF in the literature [29], it seems not appropriate to the present study population with relatively mild symptoms. As the symptom score applying to COPD patients, it may be more suitable for patients with more obvious symptoms and a higher risk of poor outcomes. Studies with large sample sizes are needed to identify IOS indicators related to symptoms. IOS reflects the pulmonary structure and mechanical characteristics during normal breathing rather than the effort-dependent forced expiratory, which might be the explanation of the better correlation for IOS with symptoms.

Overall, despite the controversial evidence on whether SAD could predict the development of COPD or asthma, it is of great importance to make a comprehensive evaluation of small airways in the early disease stage. Early detection facilitates early intervention such as smoking cessation and the utilization of small particle aerosols targeting peripheral lung. Meantime, sensitivity to changes in individuals and easy execution make IOS more suitable for long-term monitoring.

Our study has several other limitations except for the limited sample. First, we used spirometry defined SAD as the reference criterion to explore the diagnostic value of IOS. Currently, no consensus has been reached about the gold standard for SAD diagnosis. Some more intuitive detection method such as endobronchial optical coherence tomography (EB-OCT) might be more objective as reference. Second, having no predicted values adjusted by age, sex and BMI, IOS results are absolute values of individuals, which probably affects the comparability between groups. In addition, although objective languages were used in the questionnaire, the evaluation of symptoms might still be subjective. Finally, we didn't track the subjects' disease progression and treatment responses in spirometry and IOS parameters. We still don't know whether these detected SADs would develop into exact diseases like COPD or asthma. Prospective studies with a large sample size of population and more suitable scores for symptoms are needed to further explore the application of IOS in diagnosing and monitoring SAD.

\section{Conclusion}

To summarize, the current study shows that IOS is more sensitive to detect SAD than spirometry in subjects with chronic respiratory symptoms and PPF. Our data also find a better relationship for IOS parameters with symptoms in these subjects. Moreover, IOS is easy to perform and provides extended information on the central and peripheral lung. Hence, IOS could be an additional method for SAD detection in the early stage of diseases.

\footnotetext{
Abbreviations

COPD: Chronic obstructive pulmonary disease; SAD: Small airway dysfunction; PPF: Preserved pulmonary function; $\mathrm{FEV}_{1}$ : The forced expiratoryvolume in 1st s; FVC: Forced vital capacity; AHR: Airway hyper-responsiveness; BR: Bronchial reversibility; $\mathrm{FEF}_{25-75 \%}$ : The forced expiratoryflow between 25 and $75 \%$ of FVC; $\mathrm{FEF}_{50 \%}$ : The forced expiratory flowwhen $50 \%$ of FVC has been exhaled; $\mathrm{FEF}_{75 \%}$ : The forced expiratory flowwhen $75 \%$ of FVC has been exhaled; IOS: Impulse oscillometry; Rrs: Resistance of the respiratory system; Xrs: Reactance of the respiratory system; R5: Respiratory resistance at $5 \mathrm{~Hz}$; R20: Respiratory resistance at $20 \mathrm{~Hz} ; \mathrm{R} 5-\mathrm{R} 20$ : The difference between R5 and R20; X5: Reactance at $5 \mathrm{~Hz}$; Fres: Resonant frequency; AX: Area under reactance curve between Fres and5 Hz; ATS: American Thoracic Society; ERS: Europe Respiratory Society; $\mathrm{PD}_{20} \mathrm{FEV}_{1}$ : Provocative doseinducing a $20 \%$ decrease of $\mathrm{FEV}_{1}$; mMRC: Modified Medical Research Council dyspnea scale; CAT: COPD Assessment Test; ROC: Receiver operator characteristic; AUC: Area under the curve; BMI: Body mass index; LR: Likelihood ratio; EFL: Expiratory flowlimitation; EB-OCT: Endobronchial optical coherence tomography.
} 


\section{Acknowledgements \\ Not applicable.}

\section{Authors' contributions}

LLY contributed to study design, manuscript writing and data analysis. YTS contributed to data acquisition and analysis. LYQ and YJ contributed to study design and data interpretation. FLX and LL contributed to data acquisition and interpretation. LBM, WMY and LFM contributed to study design and manuscript revision. All authors Read and approved the final manuscript.

\section{Funding}

This study was partly supported by the National Nature Science Foundation of China Grant (NSFC No.81800016), "1.3.5 project for disciplines of excellence, West China Hospital, Sichuan University (ZYJC18021)", Chengdu Science and Technology Bureau (No. 2018-CY02-00064-GX), Sichuan Science and Technology Agency Grant (2019YFS0033). The funders had no roles in study design, data collection and analysis, decision to publish, or preparation of the manuscript.

\section{Availability of data and materials}

All the data will be available to other researchers on reasonable requests to the corresponding author after publication.

\section{Ethics approval and consent to participate}

This study conformed to the Declaration of Helsinki and was approved by the Ethics Committee of West China Hospital, Sichuan University, China.

\section{Consent for publication}

Not applicable.

\section{Competing interests}

The authors declare that they have no competing interests.

\section{Author details}

${ }^{1}$ Department of Respiratory and Critical Care Medicine, West China School of Medicine and West China Hospital, Sichuan University, No. 37 Guoxue Alley, Chengdu 610041, China. ${ }^{2}$ Department of Critical Care Medicine, West China School of Medicine and West China Hospital, Sichuan University, Chengdu 610041, China.

Received: 28 November 2020 Accepted: 11 February 2021 Published online: 24 February 2021

\section{References}

1. Stockley JA, Ismail AM, Hughes SM, Edgar R, Stockley RA, Sapey E. Maximal mid-expiratory flow detects early lung disease in a(1)-antitrypsin deficiency. Eur Respir J. 2017;49:1602055.

2. Schroeder JD, McKenzie AS, Zach JA, Wilson CG, Curran-Everett D, Stinson DS, Newell JD Jr, Lynch DA. Relationships between airflow obstruction and quantitative CT measurements of emphysema, air trapping, and airways in subjects with and without chronic obstructive pulmonary disease. AJR Am J Roentgenol. 2013;201:W460-470.

3. Skylogianni E, Triga M, Douros K, Bolis K, Priftis KN, Fouzas S, Anthracopoulos MB. Small-airway dysfunction precedes the development of asthma in children with allergic rhinitis. Allergol Immunopathol (Madr). 2018;46:313-21.

4. Woodruff PG, Barr RG, Bleecker E, Christenson SA, Couper D, Curtis JL, Gouskova NA, Hansel NN, Hoffman EA, Kanner RE, et al. Clinical significance of symptoms in smokers with preserved pulmonary function. N Engl J Med. 2016;374:1811-21.

5. Xiao D, Chen Z, Wu S, Huang K, Xu J, Yang L, Xu Y, Zhang X, Bai C, Kang J, et al. Prevalence and risk factors of small airway dysfunction, and association with smoking, in China: findings from a national cross-sectional study. Lancet Respir Med. 2020:8:1081-93.

6. Konstantinos Katsoulis K, Kostikas K, Kontakiotis T. Techniques for assessing small airways function: possible applications in asthma and COPD. Respir Med. 2016;119:e2-9.
7. Contoli M, Bousquet J, Fabbri LM, Magnussen H, Rabe KF, Siafakas NM, Hamid Q, Kraft M. The small airways and distal lung compartment in asthma and COPD: a time for reappraisal. Allergy. 2010;65:141-51.

8. King GG, Bates J, Berger Kl, Calverley P, de Melo PL, Dellaca RL, Farre R, Hall GL, Ioan I, Irvin CG, et al. Technical standards for respiratory oscillometry. Eur Respir J. 2020;55:1900753.

9. Skloot G, Goldman M, Fischler D, Goldman C, Schechter C, Levin $\mathrm{S}$, Teirstein A. Respiratory symptoms and physiologic assessment of ironworkers at the World Trade Center disaster site. Chest. 2004; $125: 1248-55$

10. Oppenheimer BW, Goldring RM, Herberg ME, Hofer IS, Reyfman PA, Liautaud S, Rom WN, Reibman J, Berger KI. Distal airway function in symptomatic subjects with normal spirometry following World Trade Center dust exposure. Chest. 2007;132:1275-82.

11. Su ZQ, Guan WJ, Li SY, Ding M, Chen Y, Jiang M, Chen XB, Zhong CH, Tang CL, Zhong NS. Significances of spirometry and impulse oscillometry for detecting small airway disorders assessed with endobronchial optical coherence tomography in COPD. Int J Chron Obstruct Pulmon Dis. 2018;13:3031-44

12. Williamson PA, Clearie K, Menzies D, Vaidyanathan S, Lipworth BJ. Assessment of small-airways disease using alveolar nitric oxide and impulse oscillometry in asthma and COPD. Lung. 2011;189:121-9.

13. Graham BL, Steenbruggen I, Miller MR, Barjaktarevic IZ, Cooper BG, Hall GL, Hallstrand TS, Kaminsky DA, McCarthy K, McCormack MC, et al. Standardization of spirometry 2019 Update. An Official American Thoracic Society and European Respiratory Society Technical Statement. Am J Respir Crit Care Med. 2019;200:e70-88.

14. Jian W, Gao Y, Hao C, Wang N, Ai T, Liu C, Xu Y, Kang J, Yang L, Shen H, et al. Reference values for spirometry in Chinese aged 4-80 years. J Thorac Dis. 2017;9:4538-49.

15. Coates AL, Wanger J, Cockcroft DW, Culver BH, Diamant Z, Gauvreau G, Hall GL, Hallstrand TS, Horvath I, de Jongh FHC, et al. ERS technical standard on bronchial challenge testing: general considerations and performance of methacholine challenge tests. Eur Respir J. 2017:49:1601526.

16. Colak Y, Nordestgaard BG, Vestbo J, Lange P, Afzal S. Prognostic significance of chronic respiratory symptoms in individuals with normal spirometry. Eur Respir J. 2019;54:1900734.

17. Frantz $S$, Nihlen $U$, Dencker $M$, Engstrom G, Lofdahl CG, Wollmer P. Impulse oscillometry may be of value in detecting early manifestations of COPD. Respir Med. 2012;106:1116-23.

18. Berger KI, Turetz M, Liu M, Shao Y, Kazeros A, Parsia S, Caplan-Shaw C, Friedman SM, Maslow CB, Marmor M, et al. Oscillometry complements spirometry in evaluation of subjects following toxic inhalation. ERJ Open Res. 2015;1.

19. Cottini M, Licini A, Lombardi C, Berti A. Clinical characterization and predictors of IOS-defined small-airway dysfunction in asthma. J Allergy Clin Immunol Pract. 2020;8(997-1004):e1002.

20. Burns GP, Gibson GJ. A novel hypothesis to explain the bronchconstrictor effect of deep inspiration in asthma. Thorax. 2002;57:116-9.

21. Zaidan MF, Reddy AP, Duarte A. Impedance oscillometry: emerging role in the management of chronic respiratory disease. Curr Allergy Asthma Rep. 2018:18:3.

22. Brashier B, Salvi S. Measuring lung function using sound waves: role of the forced oscillation technique and impulse oscillometry system. Breathe (Sheff). 2015;11:57-65.

23. Bickel S, Popler J, Lesnick B, Eid N. Impulse oscillometry: interpretation and practical applications. Chest. 2014;146:841-7.

24. Chiu HY, Hsiao YH, Su KC, Lee YC, Ko HK, Perng DW. Small airway dysfunction by impulse oscillometry in symptomatic patients with preserved pulmonary function. J Allergy Clin Immunol Pract. 2020;8(229-235):e223.

25. Bednarek M, Grabicki M, Piorunek T, Batura-Gabryel H. Current place of impulse oscillometry in the assessment of pulmonary diseases. Respir Med. 2020;170:105952.

26. Anderson WJ, Zajda E, Lipworth BJ. Are we overlooking persistent small airways dysfunction in community-managed asthma? Ann Allergy Asthma Immunol. 2012;109(185-189):e182.

27. Crisafulli E, Pisi R, Aiello M, Vigna M, Tzani P, Torres A, Bertorelli G, Chetta A. Prevalence of small-airway dysfunction among COPD patients with different GOLD stages and its role in the impact of disease. Respiration. 2017:93:32-41. 
28. Clement J, Landser FJ, Van de Woestijne KP. Total resistance and reactance in patients with respiratory complaints with and without airways obstruction. Chest. 1983:83:215-20.

29. Martinez CH, Murray S, Barr RG, Bleecker E, Bowler RP, Christenson SA, Comellas AP, Cooper CB, Couper D, Criner GJ, et al. Respiratory symptoms Items from the COPD Assessment Test Identify ever-smokers with preserved lung function at higher risk for poor respiratory outcomes. An analysis of the subpopulations and intermediate outcome measures in COPD study cohort. Ann Am Thorac Soc. 2017;14:636-42.

\section{Publisher's Note}

Springer Nature remains neutral with regard to jurisdictional claims in published maps and institutional affiliations.
Ready to submit your research? Choose BMC and benefit from:

- fast, convenient online submission

- thorough peer review by experienced researchers in your field

- rapid publication on acceptance

- support for research data, including large and complex data types

- gold Open Access which fosters wider collaboration and increased citations

- maximum visibility for your research: over $100 \mathrm{M}$ website views per year

At BMC, research is always in progress.

Learn more biomedcentral.com/submissions 